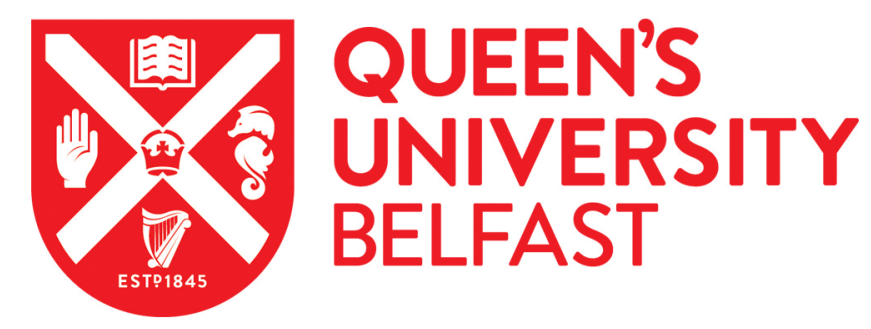

\title{
Fenofibrate and pioglitazone improve endothelial function and reduce arterial stiffness in obese glucose tolerant men
}

Ryan, K. E., McCance, D. R., Powell, L., McMahon, R., \& Trimble, E. (2007). Fenofibrate and pioglitazone improve endothelial function and reduce arterial stiffness in obese glucose tolerant men. Atherosclerosis, 194 (2)(2), e123-e130. https://doi.org/10.1016/j.atherosclerosis.2006.11.007

Published in:

Atherosclerosis

Queen's University Belfast - Research Portal:

Link to publication record in Queen's University Belfast Research Portal

\section{General rights}

Copyright for the publications made accessible via the Queen's University Belfast Research Portal is retained by the author(s) and / or other copyright owners and it is a condition of accessing these publications that users recognise and abide by the legal requirements associated with these rights.

Take down policy

The Research Portal is Queen's institutional repository that provides access to Queen's research output. Every effort has been made to ensure that content in the Research Portal does not infringe any person's rights, or applicable UK laws. If you discover content in the Research Portal that you believe breaches copyright or violates any law, please contact openaccess@qub.ac.uk. 


\title{
Fenofibrate and pioglitazone improve endothelial function and reduce arterial stiffness in obese glucose tolerant men
}

\author{
Kathryn E. Ryan ${ }^{\text {b }}$, D.R. McCance ${ }^{\mathrm{b}}$, L. Powell ${ }^{\mathrm{a}, *}$, \\ R. McMahon ${ }^{\text {b }}$, E.R. Trimble ${ }^{\mathrm{a}, \mathrm{b}}$ \\ a Department of Clinical Biochemistry \& Metabolic Medicine, Queen's University Belfast, Institute of Clinical Science A, \\ Grosvenor Road, Belfast BT12 6BJ, UK \\ b The Royal Group of Hospitals, Belfast, $U K$
}

Received 20 July 2006; received in revised form 1 November 2006; accepted 2 November 2006

\begin{abstract}
Obesity is a low grade inflammatory state associated with premature cardiovascular morbidity and mortality. Along with traditional risk factors the measurement of endothelial function, insulin resistance, inflammation and arterial stiffness may contribute to the assessment of cardiovascular risk.

We conducted a randomised placebo controlled trial to assess the effects of 12 weeks treatment with a PPAR $\alpha$ agonist (fenofibrate) and a PPAR $\gamma$ agonist (pioglitazone) on these parameters in obese glucose tolerant men. Arterial stiffness was measured using augmentation index and pulse wave velocity (PWV). E-selectin, VCAM-1 and ICAM-1 were used as markers of endothelial function.

Insulin sensitivity improved with pioglitazone treatment $(p=0.001)$ and, in keeping with this, adiponectin increased by $85.2 \%(p<0.001)$. Pro-inflammatory cytokine levels (TNF $\alpha$, IL-6 and IL-1 $\beta$ ) fell with both treatments $(p<0.01$ for TNF $\alpha$ and IL-1 $\beta, p<0.001$ for IL-6). VCAM1 and ICAM-1 were reduced with both treatments $(p<0.001$ for VCAM-1, $p<0.05$ for ICAM-1) and E-selectin improved with pioglitazone treatment $(p=0.05)$. Both treatments resulted in a fall in augmentation index. PWV fell by $17.4 \%$ with fenofibrate treatment $(p<0.001)$ and $16.3 \%$ with pioglitazone treatment $(p<0.001)$.

Pioglitazone and fenofibrate treatment of obese, glucose tolerant men reduces inflammation, improves markers of endothelial function and reduces arterial stiffness. These results suggest that treatment with PPAR agonists has potential to reduce the incidence of premature cardiovascular disease associated with obesity.
\end{abstract}

(C) 2006 Published by Elsevier Ireland Ltd.

Keywords: Obesity; PPARs; Inflammation; Arterial stiffness; Endothelial function

\section{Introduction}

Obesity is associated with premature cardiovascular morbidity and mortality. Although management of traditional risk factors is a key element in primary prevention it is suggested that up to $20 \%$ of cardiovascular events are not predicted by the information used in the Framingham coronary risk score [1]. Novel risk factors which may provide additional information to assess the probability of a vascular event include those

\footnotetext{
* Corresponding author. Tel.: +44 28 90632709; fax: +44 2890236143.

E-mail address: 1.powell@qub.ac.uk (L. Powell).
}

related to endothelial dysfunction and markers of inflammation [2].

The intact endothelium provides a physical barrier, balances thrombosis and fibrinolysis and regulates vascular tone through the secretion of vasoactive mediators which influence vascular smooth muscle contraction. Endothelial dysfunction appears to occur early in atherosclerosis and can be detected before there is clinical evidence of vascular disease [3]. The adhesion of leucocytes to the endothelium is important in the early development of atherosclerotic plaques and endothelial cell expression of adhesion molecules promotes recruitment of leucocytes at this site. Endothelial function may be assessed by quantifying plasma levels of endothelial 
products such as soluble forms of these adhesion molecules shed into the plasma from activated endothelial cells. Plasma levels of VCAM-1, ICAM-1 and E-selectin are increased in patients with cardiovascular disease [4]. Early changes in the endothelium affect the rate at which the pulse wave is propagated and also result in an altered waveform related to arterial reactivity ('stiffness').

Measurement of arterial stiffness may be used as a functional measure of the vasculature in order to estimate the risk of cardiovascular events. Arterial stiffness, which is predictive of vascular disease outcomes, can be measured by analysis of the arterial waveform to determine the pulse wave velocity (PWV) and augmentation index [5]. Increased augmentation index is associated with both all-cause and cardiovascular mortality in patients with end stage renal failure [6], while a PWV greater than $13 \mathrm{~m} / \mathrm{s}$ has been demonstrated to be a strong predictor of cardiovascular mortality in hypertension [7]. Its assessment will therefore be useful in obese patients both to identify individuals at high risk of cardiovascular disease and indicate if intervention has been beneficial.

Inflammation is central to the pathophysiology of atherosclerosis and is also thought to have a role in inducing insulin resistance. Adipose tissue is a source of inflammatory cytokines and in particular TNF $\alpha$ and IL-6; the levels of inflammatory markers may relate to adipose tissue mass [8] and potentially contribute to both the increased risk of cardiovascular disease and insulin resistance observed in obesity. By contrast increased levels of adiponectin, another cytokine derived from adipose tissue, are associated with insulin sensitivity; there is a tendency for lower levels of adiponectin in obesity [9]. The measurement of inflammatory markers, endothelial-derived adhesion molecules and arterial stiffness provides an assessment of cardiovascular risk which can be used to indicate response to treatment.

Obesity is associated with the metabolic syndrome and therefore dyslipidaemia and insulin resistance. PPAR $\alpha$ ligands are established agents in the management of hypertriglyceridaemia but may have additional effects on the arterial wall which could improve cardiovascular outcome [10]. PPAR $\gamma$ ligands were developed to improve insulin sensitivity however they demonstrate additional properties which suggest that they also could reduce cardiovascular risk in the metabolic syndrome [10]. This study was performed to assess the impact of PPAR $\alpha$ and PPAR $\gamma$ agonists on novel cardiovascular risk factors associated with obesity.

\section{Methods}

\subsection{Randomised placebo controlled trial}

A double blind randomised placebo controlled trial was conducted to examine the effect of a PPAR $\alpha$ agonist and a PPAR $\gamma$ agonist on insulin resistance, inflammation, endothelial function and arterial stiffness in obese, glucose tolerant men. Obese men $\left(\mathrm{BMI}>30 \mathrm{~kg} / \mathrm{m}^{2}\right)$ were randomised to 12 weeks treatment with either fenofibrate $160 \mathrm{mg}$ once per day (as Supralip ${ }^{\circledR}$, Fournier), pioglitazone hydrochloride (ACTOS ${ }^{\circledR}$, Takeda) $30 \mathrm{mg}$ once per day or placebo for 12 weeks. A group of lean, glucose tolerant men were recruited for comparison of baseline parameters $\left(\mathrm{BMI}<25 \mathrm{~kg} / \mathrm{m}^{2}\right)$.

Inclusion criteria were as follows: non-smoker, no cardiovascular disease, no anti-hypertensive or lipid lowering therapy, blood pressure $<160 / 90 \mathrm{mmHg}$, fasting triglycerides $<6 \mathrm{mmol} / \mathrm{l}$, total cholesterol $<7.5 \mathrm{mmol} / \mathrm{l}$, fasting plasma glucose $<6.9 \mathrm{mmol} / 1$ and/or $2 \mathrm{~h}$ glucose $<7.8 \mathrm{mmol} / 1$ during OGTT (to exclude diabetes and impaired glucose tolerance). All patients gave written informed consent and the study protocol was approved by the Ethical Committee of Queens University, Belfast.

Pre-treatment visit. Patients attended after an overnight fast and a $75 \mathrm{~g}$ oral glucose tolerance test (OGTT) was performed to determine glucose tolerance and insulin sensitivity [11]. Blood was drawn and aliquoted for lipid profile, serum adiponectin, VCAM-1, ICAM-1, E-selectin, TNF $\alpha$, IL- 6 and IL-1 $\beta$. Blood pressure was measured at the right brachial artery using the OMRON HEM$705 \mathrm{CP}$ automated sphygmomanometer. Arterial stiffness was measured by analysis of the arterial waveform to determine the augmentation index and pulse wave velocity (PWV) using the SphygmoCor ${ }^{\mathrm{TM}}$ pulse wave analysis system (AtCor Medical Pty. Ltd.). The software (SCOR2000 , version 6.3) generates a central waveform from the peripheral waveform using a validated transfer factor [5]. PWV in this study was measured by recording arterial pressure waveforms at the radial and carotid arteries sequentially.

Treatment phase. Obese subjects were randomised to treatment with placebo, pioglitazone or fenofibrate for 12 weeks.

Final visit. The procedures undertaken in pre-treatment visit were repeated for post-treatment assessment.

\subsection{Laboratory methods}

Plasma glucose, total cholesterol, HDL cholesterol and triglycerides were analysed on a VITROS 950 analyser (Ortho-Clinical Diagnostics) which uses slide based dry chemistry. LDL cholesterol was calculated using the Friedewald equation. Serum insulin was measured on an Abbott IMx analyser using a microparticle enzyme immunoassay technique (MEIA).

Adiponectin was analysed using Quantikine ${ }^{\circledR}$ human adiponectin immunoassay kit (R\&D systems). TNF $\alpha$, IL6 and IL-1 $\beta$ were measured in serum using Quantikine ${ }^{\circledR}$ high sensitivity human TNF $\alpha$, human IL-6 and human IL$1 \beta$ immunoassay kits (R\&D systems). VCAM-1, ICAM-1 and E-selectin were measured in serum using Parameter ${ }^{\circledR}$ 
Table 1

Age, BMI, blood pressure and lipid profiles of patients in each group at baseline and after treatment in the obese groups

\begin{tabular}{|c|c|c|c|c|}
\hline Group (number of subjects) & Control [9] & Placebo [15] & Pioglitazone [16] & Fenofibrate [16] \\
\hline Age (year) & $50.3 \pm 9.4$ & $48.1 \pm 8.3$ & $47.9 \pm 8.5$ & $46 \pm 7.6$ \\
\hline \multicolumn{5}{|l|}{ BMI $\left(\mathrm{kg} / \mathrm{m}^{2}\right)$} \\
\hline Pre & $23.4 \pm 1.3 * * *$ & $35.4 \pm 6.4$ & $34.1 \pm 3.6$ & $32.1 \pm 2.2$ \\
\hline Post & - & $35.0 \pm 6.8$ & $33.9 \pm 3.8$ & $32.0 \pm 2.5$ \\
\hline$\%$ change & - & -1.3 & -0.6 & -0.3 \\
\hline \multicolumn{5}{|l|}{ Waist circumference $(\mathrm{cm})$} \\
\hline Pre & $86.3 \pm 7.4 * * *$ & $116.5 \pm 17.4$ & $111.4 \pm 9.0$ & $108.5 \pm 4.1$ \\
\hline Post & - & $116.0 \pm 17.3$ & $109.4 \pm 9.2$ & $107.3 \pm 6.8$ \\
\hline$\%$ change & - & -0.4 & -1.8 & -1.1 \\
\hline \multicolumn{5}{|l|}{ Hip circumference $(\mathrm{cm})$} \\
\hline Pre & $88.2 \pm 7.1 * * *$ & $112.5 \pm 14.8$ & $107.8 \pm 7.2$ & $105.7 \pm 3.4$ \\
\hline Post & - & $112.6 \pm 15.6$ & $105.9 \pm 7.9$ & $104.9 \pm 5.5$ \\
\hline$\%$ change & - & 0.1 & -1.8 & -0.8 \\
\hline \multicolumn{5}{|l|}{ Systolic BP (mmHg) } \\
\hline Pre & $121.6 \pm 11.6^{*}$ & $133.5 \pm 8.9$ & $131.4 \pm 8.3$ & $130.3 \pm 7.0$ \\
\hline Post & - & $126.6 \pm 11.1$ & $128.3 \pm .3$ & $124.3 \pm 8.0$ \\
\hline$\%$ change & - & -5.2 & -2.4 & -4.7 \\
\hline \multicolumn{5}{|l|}{ Diastolic BP (mmHg) } \\
\hline Pre & $79.9 \pm 6.4$ & $84.5 \pm 5.9$ & $84.6 \pm 5.3$ & $84.6 \pm 5.7$ \\
\hline Post & - & $80.1 \pm 6.2$ & $82.2 \pm 4.2$ & $79.8 \pm 6.6$ \\
\hline$\%$ change & - & -5.2 & -2.8 & -5.7 \\
\hline \multicolumn{5}{|l|}{ Cholesterol } \\
\hline Pre & $4.82 \pm 0.75$ & $5.29 \pm 0.89$ & $5.27 \pm 0.65$ & $5.34 \pm 0.68$ \\
\hline Post & - & $5.18 \pm 1.08$ & $5.26 \pm 0.79$ & $4.94 \pm 0.84 *$ \\
\hline$\%$ change & - & -2.1 & -1.9 & -7.5 \\
\hline \multicolumn{5}{|l|}{ HDL cholesterol } \\
\hline Pre & $1.46 \pm 0.35^{* *}$ & $1.10 \pm 0.23$ & $1.28 \pm 0.25$ & $1.13 \pm 0.26$ \\
\hline Post & - & $1.20 \pm 0.27$ & $1.34 \pm 0.18$ & $1.24 \pm 0.27$ \\
\hline$\%$ change & - & 9.1 & 4.7 & 9.7 \\
\hline \multicolumn{5}{|l|}{ LDL cholesterol } \\
\hline Pre & $2.87 \pm 0.63$ & $3.07 \pm 0.65$ & $3.32 \pm 0.63$ & $3.30 \pm 0.76$ \\
\hline Post & - & $2.95 \pm 0.88$ & $3.21 \pm 0.63$ & $3.07 \pm 0.77$ \\
\hline$\%$ change & - & -3.9 & -3.3 & -7.0 \\
\hline \multicolumn{5}{|l|}{ Triglycerides } \\
\hline Pre & $1.11 \pm 0.28 *$ & $2.45 \pm 1.47$ & $1.88 \pm 0.84$ & $2.12 \pm 1.09$ \\
\hline Post & - & $2.27 \pm 1.3$ & $1.72 \pm 0.54$ & $1.39 \pm 0.80^{*}$ \\
\hline$\%$ change & - & -18 & -8.5 & -34.4 \\
\hline
\end{tabular}

Results are expressed as mean \pm S.D. Waist and hip circumference values were transformed to natural logarithms for statistical analysis. Lean vs. obese groups at baseline compared using ANOVA: ${ }^{*} p<0.05,{ }^{* *} p=0.01$, and ${ }^{* * *} p<0.001$. Obese groups post-treatment compared using univariate analysis of covariance.

human sVCAM-1, sICAM-1 and sE-selectin immunoassay kits (R\&D systems).

\subsection{Statistics}

Statistical advice was obtained from the Northern Ireland Clinical Research Support Centre, Research and Development Office (NI). Statistical comparisons were performed using SPSS version 12.0. Lean and obese groups were compared at baseline by ANOVA. The obese groups were compared after treatment using univariate analysis of covariance with pre-treatment values as a covariant; this analyses the degree of change observed for significance. Nonparametric data were log transformed to natural logarithms to allow parametric testing.

\section{Results}

\subsection{Body mass index}

As patients were recruited on the basis of body mass index the lean group had BMIs which would be categorised as normal. The obese groups had BMIs of greater than $30.0 \mathrm{~kg} / \mathrm{m}^{2}$ before treatment and among the obese groups there was no significant weight change over the study period (Table 1).

\subsection{Blood pressure}

The normal weight group had lower systolic pressure $(p<0.05)$ but similar diastolic pressure compared with base- 
line levels in the obese groups. Blood pressure was not significantly altered by treatment.

\subsection{Lipid profile}

In keeping with dyslipidaemia associated with the metabolic syndrome, HDL-cholesterol was higher $(p=0.01)$ and triglycerides lower $(p<0.05)$ in the normal weight individuals relative to the obese groups (Table 1). After fenofibrate treatment total cholesterol fell by $7.5 \%(p<0.05)$ and triglycerides improved by $34.4 \%(p<0.05)$. There was no significant change in lipid profile with either placebo or pioglitazone.

\subsection{Oral glucose tolerance}

Obese patients had higher plasma glucose at 30 and $60 \mathrm{~min}$ than the lean group during the OGTT but fasting levels were similar (Fig. 1). Plasma glucose was less than $7.8 \mathrm{mmol} / 1$ at $120 \mathrm{~min}$ after $75 \mathrm{~g}$ of oral glucose indicating that, despite obesity, the patients who entered the treatment phase of the study had normal glucose tolerance.

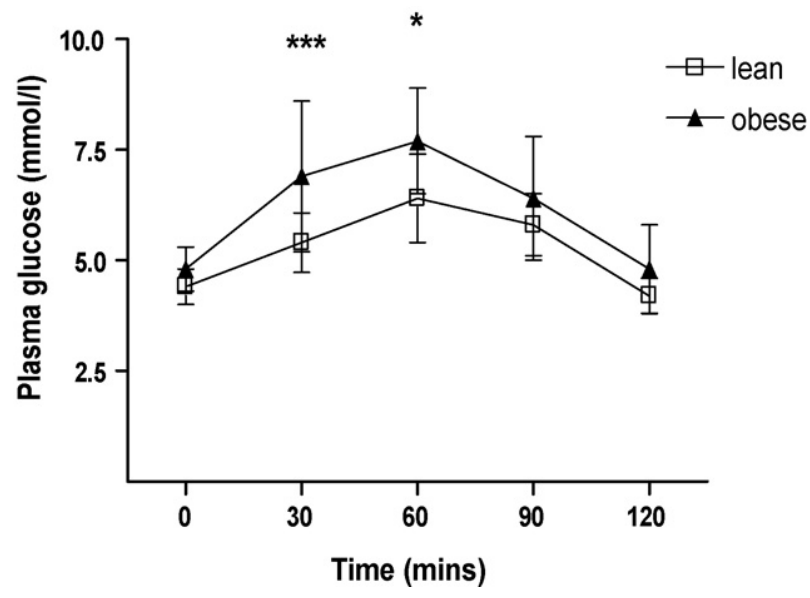

Fig. 1. Graph of mean plasma glucose at $30 \mathrm{~min}$ intervals during $75 \mathrm{~g}$ OGTT in lean and obese subjects. Error bars indicate S.D. Number of subjects: lean, $n=9$; obese, $n=47$. Lean vs. obese groups at each time point compared using ANOVA: ${ }^{*} p<0.05$ and ${ }^{* * *} p<0.001$

Table 2

Fasting insulin and integrated insulin response to oral glucose in all groups at baseline and after treatment in obese subjects

\begin{tabular}{|c|c|c|c|c|}
\hline Groups (number of subjects) & Control [9] & Placebo [15] & Pioglitazone [16] & Fenofibrate [16] \\
\hline \multicolumn{5}{|l|}{ Fasting insulin (mU/ml) } \\
\hline Pre & $7.1 \pm 2.3^{* *}$ & $22.6 \pm 11.1$ & $16.9 \pm 7.2$ & $17.3 \pm 7.8$ \\
\hline Post & - & $20.5 \pm 10.8$ & $10.2 \pm 4.4^{*}$ & $12.8 \pm 5.0^{*}$ \\
\hline$\%$ change & - & -9.3 & -39.6 & -26.0 \\
\hline \multicolumn{5}{|l|}{ Insulin AUC (mU/ml $180 \mathrm{~min})$} \\
\hline Pre & $113.5 \pm 53.3^{* * *}$ & $298.7 \pm 1696$ & $246.9 \pm 1878$ & $227.9 \pm 1015$ \\
\hline Post & - & $297.9 \pm 208.3$ & $158.3 \pm 83.2^{\# \# \#}$ & $216.7 \pm 92.2$ \\
\hline$\%$ change & - & -0.3 & -35.9 & -4.9 \\
\hline
\end{tabular}

Integrated insulin response was calculated using area under the curve (AUC) of serum insulin at $30 \mathrm{~min}$ intervals up to $180 \mathrm{~min}$ during $75 \mathrm{~g}$ OGTT. Fasting insulin and insulin AUC values were transformed to natural logarthims for statistical analysis. Results are expressed as mean \pm S.D. Lean vs. obese groups at baseline compared using ANOVA: ${ }^{* *} p<0.01$ and ${ }^{* * *} p<0.001$. Obese groups post-treatment compared using univariate analysis of covariance: ${ }^{*} p<0.05$ and $\#=0.001$.

Table 3

Serum levels of E-selectin, ICAM-1 and VCAM-1 at baseline in all groups and after treatment in the obese groups

\begin{tabular}{|c|c|c|c|c|}
\hline Groups (number of subjects) & Control [9] & Placebo [15] & Pioglitazone [16] & Fenofibrate [16] \\
\hline \multicolumn{5}{|l|}{ E-selectin (ng/ml) } \\
\hline Pre & $43.1 \pm 13.1$ & $57.6 \pm 20.6$ & $62.5 \pm 23.3$ & $53.2 \pm 20.8$ \\
\hline Post & - & $59.5 \pm 27.5$ & $51.6 \pm 20.2^{\sim}$ & $50.9 \pm 20.9$ \\
\hline$\%$ change & - & 3.3 & -17.4 & -4.3 \\
\hline \multicolumn{5}{|l|}{ ICAM-1 (ng/ml) } \\
\hline Pre & $266.3 \pm 31.2$ & $285.8 \pm 57.1$ & $276.9 \pm 64.6$ & $293.5 \pm 87.5$ \\
\hline Post & - & $289.5 \pm 64.2$ & $257.3 \pm 65.1^{*}$ & $257.9 \pm 36.7^{*}$ \\
\hline$\%$ change & - & 1.3 & -7.1 & -12.1 \\
\hline \multicolumn{5}{|l|}{ VCAM-1 (ng/ml) } \\
\hline Pre & $567.7 \pm 134.7$ & $632.8 \pm 222.8$ & $682.2 \pm 246.5$ & $676.6 \pm 297.4$ \\
\hline Post & - & $648.4 \pm 220.7$ & $583.4 \pm 212.4^{* *}$ & $574.9 \pm 229.3^{* *}$ \\
\hline$\%$ change & - & 2.5 & -14.5 & -15.0 \\
\hline
\end{tabular}

Results are expressed as mean \pm S.D. Lean vs. obese groups at baseline compared using ANOVA. Obese groups post-treatment compared using univariate analysis of covariance: ${ }^{\sim} p=0.05,{ }^{*} p<0.05$, and ${ }^{* *} p<0.01$. 
Table 4

Mean plasma levels of cytokines at baseline in all groups and after treatment in obese groups

\begin{tabular}{|c|c|c|c|c|}
\hline Groups (number of subjects) & Control [9] & Placebo [15] & Pioglitazone [16] & Fenofibrate [16] \\
\hline \multicolumn{5}{|l|}{ Plasma TNF $\alpha(\mathrm{pg} / \mathrm{ml})$} \\
\hline Pre & $1.27 \pm 0.23^{*}$ & $2.09 \pm 1.38$ & $1.63 \pm 0.49$ & $2.00 \pm 1.07$ \\
\hline Post & - & $2.00 \pm 1.22$ & $1.43 \pm 0.42^{\# \#}$ & $1.48 \pm 0.4^{\# \#}$ \\
\hline$\%$ change & - & -4.3 & -12.3 & -26.0 \\
\hline \multicolumn{5}{|l|}{ Plasma IL-6 (pg/ml) } \\
\hline Pre & $1.55 \pm 0.35$ & $1.61 \pm 0.65$ & $1.90 \pm 0.95$ & $1.70 \pm 0.65$ \\
\hline Post & - & $1.89 \pm 0.74$ & $1.29 \pm 0.43^{\# \# \#}$ & $1.33 \pm 0.41^{\# \#+}$ \\
\hline$\%$ change & - & 17.4 & -32.1 & -21.8 \\
\hline \multicolumn{5}{|l|}{ Plasma IL-1 $\beta$ (pg/ml) } \\
\hline Pre & $0.09 \pm 0.07$ & $0.24 \pm 0.16$ & $0.30 \pm 0.28$ & $0.40 \pm 0.30$ \\
\hline Post & - & $0.23 \pm 0.16$ & $0.13 \pm 0.24^{\# \#}$ & $0.18 \pm 0.31^{\# \#}$ \\
\hline$\%$ change & - & -4.2 & -56.7 & -55.0 \\
\hline \multicolumn{5}{|l|}{ Adiponectin $(\mu \mathrm{g} / \mathrm{ml})$} \\
\hline Pre & $6.5 \pm 3.2$ & $4.9 \pm 2.0$ & $6.1 \pm 2.3$ & $5.2 \pm 1.8$ \\
\hline Post & - & $5.0 \pm 2.0$ & $11.3 \pm 4.6^{\# \# \#}$ & $5.0 \pm 1.7$ \\
\hline$\%$ change & - & 2.0 & 85.2 & -3.8 \\
\hline
\end{tabular}

Results are expressed as mean \pm S.D. Values for TNF $\alpha$ and IL-6 were transformed to natural logarithms for statistical analysis. For TNF $\alpha$, IL-6 and adioiponectin: lean vs. obese groups were compared at baseline using ANOVA: ${ }^{\#} p<0.01$. Obese groups post-treatment compared using univariate analysis of covariance: ${ }^{*} p<0.01,{ }^{\# \#} p<0.01$ and ${ }^{\# \#} p<0.001$. IL-1 $\beta$ : lean vs. obese groups at baseline compared using one-way ANOVA by ranks. Obese groups post-treatment analysed by calculating the change (before-after) and comparing these using a Kruskal-Wallis one-way analysis of variance by ranks: ${ }^{\# \#} p<0.01$.

\subsection{Insulin resistance}

Two surrogate markers of insulin resistance were used: fasting insulin and the integrated insulin response to a $75 \mathrm{~g}$ oral glucose tolerance test (measured by the area under the curve of the serum insulin levels up to $3 \mathrm{~h} \mathrm{[11]).}$ Both these parameters were much lower in the normal weight group (both $p<0.001$ ) compared to the obese subjects (Table 2). Fasting insulin improved by $39.6 \%$ in the pioglitazone treated group and by $26 \%$ with fenofibrate treatment (both $p<0.05$ when compared with placebo). The integrated insulin response was significantly reduced only by pioglitazone treatment where it fell by $35.9 \%$ $(p=0.001)$.

\subsection{Soluble adhesion molecules}

ICAM-1, VCAM-1 and E-selectin were found to vary widely among individuals with a coefficient of variation of approximately $20 \%$ for ICAM- 1 and 35\% for VCAM-1 and E-selectin (Table 3). Both pioglitazone treatment and fenofibrate resulted in significant falls in ICAM-1 $(p<0.05)$ and VCAM-1 $(p<0.01)$ (Table 3). Absolute E-selectin levels were similar following fenofibrate and pioglitazone treatment but this represented a non-significant fall of $4.3 \%$ with fenofibrate and significant fall of $17.4 \%$ with pioglitazone (Table 3 ). These results indicate an improvement in endothelial function with both pioglitazone and fenofibrate. In the group receiving pioglitazone treatment the change in VCAM-1 correlated with the improvement in insulin sensitivity measured by the integrated insulin response $(r=0.47, p=0.029)$ (Table 3).
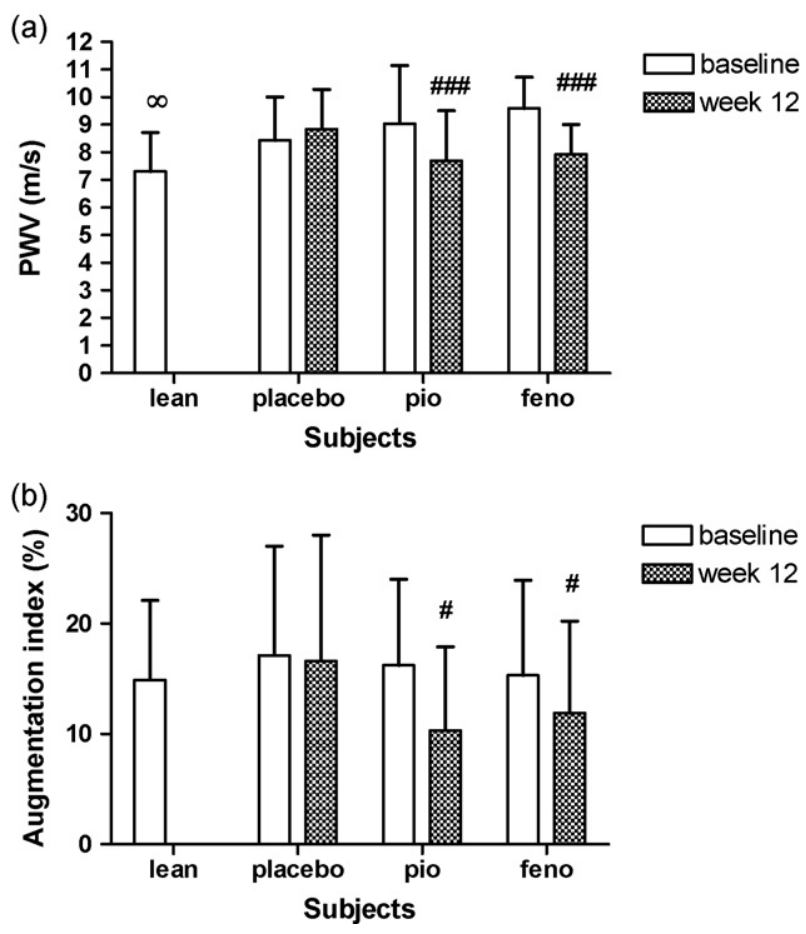

Fig. 2. Mean PWV and augmentation index in all groups at baseline and obese groups after treatment: (a) PWV and (b) augmentation index; pio, pioglitazone; feno, fenofibrate. Numbers in study: lean, $n=9$; placebo, $n=15$; pio, $n=16$; feno, $n=16$. Error bars indicate S.D. Lean vs. obese groups at baseline compared using ANOVA: ${ }^{\infty} p=0.012$. Obese groups post-treatment compared using univariate analysis of covariance: ${ }^{\#} p<0.05$; \#\#\# $p<0.001$. 


\subsection{Cytokines/adipokines}

Baseline $\mathrm{TNF} \alpha$ was significantly lower in the normal weight group; all three pro-inflammatory cytokines measured fell with both active treatments in the obese subjects (Table 4). Adiponectin showed a tendency (not significant) to be lower in obese groups at baseline and rose significantly (by $85.2 \%, p<0.001$ ) in the group receiving pioglitazone (Table 4); fenofibrate and placebo treatment did not cause any change in adiponectin levels.

\subsection{Arterial stiffness}

Arterial stiffness as measured by PWV was lower in lean individuals $(p=0.012)$. Augmentation index is recognised to be variable among individuals; this was reflected in the large standard deviation found (Fig. 2(b)). Both augmentation index (Fig. 2(b)) and PWV (Fig. 2(a)) were reduced significantly after each treatment compared with placebo $(p<0.05$ for augmentation index and $p<0.001$ for PWV). Blood pressure, which influences arterial stiffness, did not change significantly in any of the three groups suggesting that changes in arterial stiffness measured in this study are due to factors other than this.

\section{Discussion}

As the prevalence of obesity increases strategies to effectively tackle both obesity and its consequences are therefore necessary. Subjects in this study were recruited in the early phase of the syndrome(s) associated with obesity; that is, they were clinically well, had normal glucose tolerance and were without symptomatic cardiovascular disease. However, they were insulin resistant, a state that precedes the onset of type 2 diabetes and is an independent risk factor for the development of cardiovascular disease [12]. Treatment of obesity with diet and exercise leading to weight reduction would be an ideal strategy but this approach yields suboptimal results since, for most affected individuals, these positive life-style changes prove difficult to maintain. The present study demonstrates the potential role of PPAR agonists in reducing the vascular risk factors associated with obesity.

Inflammation appears to play an important role in the development of insulin resistance and endothelial dysfunction in obese individuals. The inflammatory adipokines TNF $\alpha$ and IL- 6 are implicated in the pathogenesis of insulin resistance. In contrast to TNF $\alpha$ and IL-6, adiponectin reduces plasma glucose, increases fatty acid oxidation in skeletal muscle and augments insulin induced inhibition of hepatic glucose output [13]. The production of TNF $\alpha$ and IL-6 increase [14] while adiponectin is reduced [9] in obesity. Similar to the current study Tsigos et al. reported that plasma $\mathrm{TNF} \alpha$ positively correlates with abdominal obesity [15]; however, there is no consensus about the contribution of fat depots to circulating levels of TNF $\alpha$ [14]. The increase in pro-inflammatory cytokines in adipose tissue is closely linked to the increase in adipose tissue resident macrophages [16]. The thiazolidinediones (TZDs) are known to have anti-inflammatory properties; one of the TZDs, rosiglitazone, has been shown to reduce the number of macrophages in white adipose tissue in mice [16], and hence to reduced macrophage-derived inflammatory cytokines. TZDs also promote adipocyte differentiation and it is suggested that the smaller adipocytes which result from this are more insulin sensitive than large adipocytes [17]. In the present study pioglitazone treatment caused a marked increase in plasma adiponectin levels as well as a reduction in TNF $\alpha$ and IL-6. Fenofibrate treatment has also been shown to reduce inflammation. For example, fibrates inhibit AP-1 and NFKB mediated transcription of IL-6 in VSMC [18]. These effects may be widespread and mediate the direct antiinflammatory effects of fenofibrate. Fibrates may potentially improve insulin sensitivity through their effects on lipids and inflammatory markers [10]. However, although fenofibrate treatment did result in a fall in total cholesterol, triglycerides and circulating pro-inflammatory cytokines it did not improve adiponectin levels or insulin sensitivity in this study. It is possible that the differences in adiponectin response may explain in part why pioglitazone had a more marked effect on insulin sensitivity than fenofibrate.

The improvement in circulating cytokines and adipokines during treatment with PPAR $\alpha$ and PPAR $\gamma$ agonists was paralleled by reduced levels of circulating adhesion molecules. E-selectin, important for initiating the capture and adhesion of leucocytes, is produced only by the endothelium whereas ICAM-1 and VCAM-1 have a wider tissue distribution that may limit the degree to which elevated plasma levels can be attributed to endothelial dysfunction [4]. The elevated levels of pro-inflammatory cytokines in obesity may promote the expression of all adhesion molecules and contribute to the development of atherosclerosis. NFKB may be a final common pathway in regulating expression of cell adhesion molecules with inflammation, dyslipidaemia, oxidative stress and advanced glycation endproducts influencing it. In health nitric oxide (NO) inhibits NFKB activation [19] and when there is impairment of NO production, as is found in endothelial dysfunction preceding atherosclerosis [3], this inhibitory effect is lost. Fenofibrate has been found to increase the half-life of eNOS by stabilizing its mRNA and this may be a mechanism through which fibrates improve endothelial function [20]. There may also be direct effects of PPAR agonists on adhesion molecule production since endothelial cells possess PPAR receptors and reduced adhesion molecule expression has been shown in vitro [21].

The improvement in E-selectin, VCAM-1 and ICAM-1 in vivo with pioglitazone has not been previously reported. In endothelial cell culture troglitazone treatment resulted in a parallel fall in expression of adhesion molecules and NFkB [22]. This fall may be due to increased NO levels and PPAR $\gamma$ ligands increase NO release in vitro but do not increase eNOS expression or protein levels [23]. Pioglita- 
zone is an insulin sensitizer but the direct effect of insulin on adhesion molecules is uncertain. Adiponectin, which in the present study increased with pioglitazone treatment, has been shown to attenuate the $\mathrm{TNF} \alpha$ stimulated increase in E-selectin, VCAM-1, and ICAM-1 on the cell surface of endothelial cells in culture [24]. There are, therefore, several mechanisms acting on the anti-inflammatory pathway which may produce the improvement in endothelial function with pioglitazone.

Fenofibrate, as a PPAR $\alpha$ agonist, has potent triglyceride lowering effects with a modest effect on cholesterol. The mechanism for the fall in VCAM-1 and ICAM-1 with this treatment may be due to its lipid lowering properties particularly the reduction of VLDL. Fenofibrate has also been shown to have anti-inflammatory effects and improve insulin sensitivity both of which may alter VCAM-1, ICAM-1 and E-selectin levels. Fenofibrate reduces NFкB binding to its recognition site on the VCAM-1 promoter thus down regulating $\mathrm{NF}_{\kappa} \mathrm{B}$ activity and VCAM-1 expression [25].

The vascular stiffness associated with obesity may be a direct effect of insulin resistance, fatty acids or proinflammatory cytokines. An increased augmentation index has been demonstrated in patients with rheumatoid arthritis who did not have evidence of vasculitis, cardiovascular disease or known cardiac risk factors [26]. This would suggest that inflammation per se may increase arterial stiffness and contribute to the excess cardiovascular mortality in rheumatoid arthritis. Obesity is recognised to be an inflammatory state and treatments which reduce this such as PPAR agonists may be important in improving vascular outcomes in this group of patients. The improvements in arterial stiffness with fenofibrate demonstrated in this study are novel and may be the result of a reduction in free fatty acids and anti-inflammatory effects.

Like fenofibrate, pioglitazone also reduced inflammation and the fall in TNF $\alpha$ in particular may reduce arterial stiffness. TZDs have a marked influence on insulin sensitivity and insulin resistant states such as type 2 diabetes and impaired glucose tolerance which are associated with arterial stiffness [27]. Improving insulin sensitivity with pioglitazone may therefore be an important mechanism by which PPAR $\gamma$ agonists reduce arterial stiffness. Insulin promotes the release of nitric oxide [28] but insulin resistance, and therefore hyperinsulinaemia, is correlated with increased arterial stiffness and reduced responsiveness to exogenous insulin. This may reflect a difference in the response of the endothelium to insulin in insulin sensitive and insulin resistant states. Indeed a correlation has been shown between reduced insulin stimulated glucose uptake and reduced augmentation index in response to insulin infusion in non-diabetic men [29]. This suggests that in insulin resistant states the blood vessels are also less reactive to insulin stimulation.

The value of improving arterial stiffness is highlighted by a study which reports that augmentation index measured using the same technique as used in this project correlated with coronary atherosclerosis found at angiography [30].
In conclusion this investigation has demonstrated that a PPAR $\alpha$ agonist (fenofibrate) and a PPAR $\gamma$ agonist (pioglitazone) reduce inflammation, adhesion molecules and arterial stiffness in obese glucose tolerant men suggesting that there is evidence to explore the long-term use of these agents in prevention of coronary heart disease in these conditions.

\section{Acknowledgements}

This work was supported by a research fellowship to KER from the Research and Development Office, Department of Health, Social Services and Public Safety, Northern Ireland. Fournier Pharma donated the fenofibrate used in the study.

\section{References}

[1] Grundy SM, Bazzarre T, Cleeman J, et al. Prevention conference V: beyond secondary prevention: identifying the high-risk patient for primary prevention: medical office assessment: writing group I. Circulation 2000;101:E3-E11.

[2] Gonzalez MA, Selwyn AP. Endothelial function, inflammation, and prognosis in cardiovascular disease. Am J Med 2003;115(suppl 8A):99S-106S.

[3] Ross R. Atherosclerosis - an inflammatory disease. N Engl J Med 1999;340:115-26.

[4] Blann AD, Lip GY. Cell adhesion molecules in cardiovascular disease: what can soluble levels tell us? Heart 1999;81:101-2.

[5] Karamanoglu M, O'Rourke MF, Avolio AP, Kelly RP. An analysis of the relationship between central aortic and peripheral upper limb pressure waves in man. Eur Heart J 1993;14:160-7.

[6] Blacher J, Guerin AP, Pannier B, et al. Impact of aortic stiffness on survival in end-stage renal disease. Circulation 1999;99:2434-9.

[7] Blacher J, Asmar R, Djane S, London GM, Safar ME. Aortic pulse wave velocity as a marker of cardiovascular risk in hypertensive patients. Hypertension 1999;33:1111-7.

[8] Yudkin JS, Stehouwer CD, Emeis JJ, Coppack SW. C-reactive protein in healthy subjects: associations with obesity, insulin resistance, and endothelial dysfunction: a potential role for cytokines originating from adipose tissue? Arterioscler Thromb Vasc Biol 1999;19:972-8.

[9] Gable DR, Hurel SJ, Humphries SE. Adiponectin and its gene variants as risk factors for insulin resistance, the metabolic syndrome and cardiovascular disease. Atherosclerosis 2006;188:231-44.

[10] Kostadinova R, Wahli W, Michalik L. PPARs in diseases: control mechanisms of inflammation. Curr Med Chem 2005;12:2995-3009.

[11] Yeni-Komshian H, Carantoni M, Abbasi F, Reaven GM. Relationship between several surrogate estimates of insulin resistance and quantification of insulin-mediated glucose disposal in 490 healthy nondiabetic volunteers. Diabetes Care 2000;23:171-5.

[12] Despres JP, Lamarche B, Mauriege P, et al. Hyperinsulinemia as an independent risk factor for ischemic heart disease. $\mathrm{N}$ Engl $\mathrm{J}$ Med 1996;334:952-7.

[13] Spranger J, Kroke A, Mohlig M, et al. Adiponectin and protection against type 2 diabetes mellitus. Lancet 2003;361:226-8.

[14] Trayhurn P, Wood IS. Adipokines: inflammation and the pleiotropic role of white adipose tissue. Br J Nutr 2004;92:347-55.

[15] Tsigos C, Kyrou I, Chala E, et al. Circulating tumor necrosis factor alpha concentrations are higher in abdominal versus peripheral obesity. Metabolism 1999;48:1332-5.

[16] Tsuchida A, Yamauchi T, Takekawa S, et al. Peroxisome proliferatoractivated receptor (PPAR) $\{$ alpha $\}$ activation increases adiponectin receptors and reduces obesity-related inflammation in adipose tissue: 
comparison of activation of $\operatorname{PPAR}\{$ alpha $\}$, PPAR $\{$ gamma $\}$, and their combination. Diabetes 2005;54:3358-70.

[17] Tafuri SR. Troglitazone enhances differentiation, basal glucose uptake, and Glut1 protein levels in 3T3-L1 adipocytes. Endocrinology 1996;137:4706-12.

[18] Staels B, Koenig W, Habib A, et al. Activation of human aortic smooth-muscle cells is inhibited by PPARalpha but not by PPARgamma activators. Nature 1998;393:790-3.

[19] De CR, Libby P, Peng HB, et al. Nitric oxide decreases cytokineinduced endothelial activation. Nitric oxide selectively reduces endothelial expression of adhesion molecules and proinflammatory cytokines. J Clin Invest 1995;96:60-8.

[20] Goya K, Sumitani S, Xu X, et al. Peroxisome proliferator-activated receptor alpha agonists increase nitric oxide synthase expression in vascular endothelial cells. Arterioscler Thromb Vasc Biol 2004;24:658-63.

[21] Imamoto E, Yoshida N, Uchiyama K, et al. Inhibitory effect of pioglitazone on expression of adhesion molecules on neutrophils and endothelial cells. Biofactors 2004;20:37-47.

[22] Cominacini L, Garbin U, Pasini AF, et al. The expression of adhesion molecules on endothelial cells is inhibited by troglitazone through its antioxidant activity. Cell Adhes Commun 1999;7:223-31.

[23] Calnek DS, Mazzella L, Roser S, Roman J, Hart CM. Peroxisome proliferator-activated receptor gamma ligands increase release of nitric oxide from endothelial cells. Arterioscler Thromb Vasc Biol $2003 ; 23: 52-7$.
[24] Ouchi N, Kihara S, Arita Y, et al. Novel modulator for endothelial adhesion molecules: adipocyte-derived plasma protein adiponectin. Circulation 1999;100:2473-6.

[25] Xu X, Otsuki M, Saito H, et al. PPARalpha and GR differentially downregulate the expression of nuclear factor-kappaB-responsive genes in vascular endothelial cells. Endocrinology 2001;142:3332-9.

[26] Klocke R, Cockcroft JR, Taylor GJ, Hall IR, Blake DR. Arterial stiffness and central blood pressure, as determined by pulse wave analysis, in rheumatoid arthritis. Ann Rheum Dis 2003;62:414-8.

[27] Salomaa V, Riley W, Kark JD, Nardo C, Folsom AR. Noninsulin-dependent diabetes mellitus and fasting glucose and insulin concentrations are associated with arterial stiffness indexes. The ARIC study. Atherosclerosis risk in communities study. Circulation 1995;91:1432-43.

[28] Zeng G, Quon MJ. Insulin-stimulated production of nitric oxide is inhibited by wortmannin. Direct measurement in vascular endothelial cells. J Clin Invest 1996;98:894-8.

[29] Westerbacka J, Seppala-Lindroos A, Yki-Jarvinen H. Resistance to acute insulin induced decreases in large artery stiffness accompanies the insulin resistance syndrome. J Clin Endocrinol Metab 2001;86: $5262-8$.

[30] Weber T, Auer J, O'Rourke MF, et al. Arterial stiffness, wave reflections, and the risk of coronary artery disease. Circulation 2004;109:184-9. 